\title{
Explaining Sex Differences in Cardiac Resynchronisation Therapy Outcome
}

\author{
Alwin Zweerink, ${ }^{1,2}$ Elise Bakelants, ${ }^{1}$ Cornelis P Allaart ${ }^{2}$ and Haran Burri ${ }^{1}$ \\ 1. Department of Cardiology, University Hospital of Geneva, Geneva, Switzerland; 2. Department of Cardiology and Amsterdam \\ Cardiovascular Sciences, Amsterdam University Medical Centers, Vu Medical Center, Amsterdam, The Netherlands
}

W omen are less likely to receive cardiac resynchronisation therapy (CRT), yet accumulating evidence suggests that they derive more benefit than men. This review summarises existing literature elucidating why sex-specific differences in CRT outcome exist. First it is demonstrated that among CRT candidates, women exhibit different risk factors resulting in better heart failure prognosis, irrespective of CRT. Second, women more often display factors associated with good response to CRT, such as non-ischaemic cardiomyopathy with lower scar burden and left bundle branch block at shorter QRS duration, possibly due to smaller heart size. Whether differences in CRT outcome can be attributed to these factors or if, after correction, a true sex difference exists, remains a topic of debate.

\section{Keywords}

Cardiac resynchronisation therapy, pacing, heart failure, sex, women

Disclosures: Cornelis P Allaart has received speaker fees from Biotronik, and research grants from Biotronik, Boston Scientific and Biosense Webster. Haran Burri has received speaker fees and research grants from Abbott, Biotronik, Boston Scientific, Medtronic and MicroPort. Alwin Zweerink and Elise Bakelants have no financial or non-financial relationships or activities to declare in relation to this article.

Compliance with Ethics: This article involves a review of the literature and did not involve any studies with human or animal subjects performed by any of the authors.

Authorship: The named authors meet the Internationa Committee of Medical Journal Editors (ICMJE) criteria for authorship of this manuscript, take responsibility for the integrity of the work as a whole, and have given final approval for the version to be published.

Access: This article is freely accessible at touchCARDIO.com (C) Touch Medical Media 2020

Received: 29 June 2020

Accepted: 20 August 2020

Published Online: 20 October 2020

Citation: European Journal of Arrhythmia

\& Electrophysiology. 2020;6(1):17-23

Corresponding Author: Alwin Zweerink,

Cardiology Department, University Hospital of Geneva,

Rue Gabrielle-Perret-Gentil 4, CH-1211 Geneva,

Switzerland. E: a.zweerink@amsterdamumc.nl

Support: No funding was received in

the publication of this article.
Over the past years, several reports have drawn attention to the need to consider sex-specific differences in cardiac resynchronisation therapy (CRT). Most importantly, there is growing concern on the underrepresentation of women in CRT landmark trials, which laid the foundation for present guidelines. Patients with symptomatic heart failure, reduced left ventricular ejection fraction (LVEF) $\leq 35 \%$ and electrical conduction delay on the electrocardiogram (ECG) may benefit from CRT. International guidelines use a QRS duration entry criterion of 120 ms (USA) or 130 ms (Europe) before considering CRT. ${ }^{1,2}$ The level of recommendation depends on QRS morphology and QRS duration with a higher class of recommendation (i.e., class I indication) for patients with strict left bundle branch block (LBBB) morphology and QRS duration $\geq 150 \mathrm{~ms}$. Although these cut-off values were derived from landmark trials with predominantly male subjects, the same criteria are currently used for women. Following these criteria, women are less likely to receive CRT, yet accumulating evidence suggests that they derive more benefit than men. Previous review-reports advocated for the existence of this sex paradox and called for new sex-specific guidelines. ${ }^{3-6}$ However, an overview of the mechanisms that explain sex differences in CRT outcome is currently lacking. This review summarises existing literature elucidating why sex-specific differences in CRT may exist.

\section{The sex paradox}

Females account for $17-33 \%$ of the study population in landmark trials. ${ }^{7-12}$ Half of these trials (MADIT-CRT, MIRACLE, RAFT) suggested greater effect of CRT on outcome in women. Others (CARE-HF, COMPANION, REVERSE) did not reveal a sex-related difference, although they may have lacked power to do this (Table 1). ${ }^{7-12,28,33,41}$ Two meta-analyses combined data from multiple landmark trials. Zusterzeel et al. pooled data from MADIT-CRT, RAFT, REVERSE comparing effects of a CRT defibrillator (CRT-D) versus an implantable cardioverter defibrillator (ICD) amongst 4,076 patients (22\% women). ${ }^{16}$ In this study, women showed an overall favourable effect of CRT-D, and women with LBBB benefitted from CRT-D at a shorter QRS duration than men. Linde et al. pooled data from CARE-HF, MIRACLE, RAFT and REVERSE comparing CRT versus no CRT amongst 3,776 patients (21\% women). ${ }^{17}$ Women tended to obtain greater benefit from CRT, but sex was not an independent predictor of clinical outcome.

Over two decades, numerous studies have compared CRT outcome between women and men Six meta-analyses and registries, ${ }^{18-23}$ each containing over 10,000 patients, consistently showed better clinical outcomes for women, both on mortality and heart failure endpoints (Table 2). ${ }^{18-23}$ Leyva et al. recently published results from a large English database comprising almost 44,000 patients (25\% women) confirming sex-specific differences in CRT outcome (Figure 1). ${ }^{20}$ Meanwhile, these data also underline the underrepresentation of women in the real-world CRT population. The Swedish Heart Failure Registry showed that female sex was an independent predictor of CRT underutilisation. ${ }^{24}$ Moreover, Chatterjee et al. showed, in a large cross-sectional study with over 300,000 patients, that sex differences in CRT-D implantation increased over time. ${ }^{25}$ These results have led to the general consensus that (i) women are less likely to receive CRT than men; (ii) underutilisation of CRT in women results from using male-oriented guideline criteria (and a lower referral rate/higher refusal rate); (iii) women potentially derive more benefit from CRT than men. ${ }^{26}$ 
Table 1: Sex comparison in cardiac resynchronisation therapy landmark trials

\begin{tabular}{|c|c|c|c|c|c|c|}
\hline Study & Women, n (\%) & Selection criteria & Randomisation & Endpoint & HR for events $(95 \% \mathrm{CI})$ & Sex comparison \\
\hline CARE-HF' & $216(27 \%)$ & $\begin{array}{l}\text { NYHA class III-IV } \\
\text { QRSd } \geq 120 \mathrm{~ms} \\
\text { LVEF } \leq 35 \% \\
\text { LVEDDi } \geq 30 \mathrm{~mm}\end{array}$ & OMT versus OMT + CRT-P & Death or HF hospitalisation & $\begin{array}{l}\text { Women: } 0.64(0.42-0.97) \\
\text { Men: } 0.62(0.49-0.79)\end{array}$ & No sex difference \\
\hline COMPANION ${ }^{8}$ & 495 (33\%) & $\begin{array}{l}\text { NYHA class III-IV } \\
\text { QRSd } \geq 120 \mathrm{~ms} \\
\text { LVEF } \leq 35 \%\end{array}$ & OMT versus OMT + CRT-D & Death & $\begin{array}{l}\text { Women: } 0.58(0.25-1.13) \\
\text { Men: } 0.63(0.40-0.90)\end{array}$ & No sex difference \\
\hline MADIT-CRT 11,14 & $453(25 \%)$ & $\begin{array}{l}\text { NYHA class I- } I \\
\text { QRSd } \geq 130 \mathrm{~ms} \\
\text { LVEF } \leq 30 \%\end{array}$ & ICD versus CRT-D & Death or HF events & $\begin{array}{l}\text { Women: } 0.37(0.22-0.61) \\
\text { Men: } 0.76(0.59-0.97)\end{array}$ & Favours women \\
\hline MIRACLE 7,13 & 107 (33\%) & $\begin{array}{l}\text { NYHA class III-IV } \\
\text { QRSd } \geq 130 \mathrm{~ms} \\
\text { LVEF } \leq 35 \% \\
\text { LVEDD } \geq 55 \mathrm{~mm}\end{array}$ & CRT-ON versus CRT-OFF & Death or HF hospitalisation & $\begin{array}{l}\text { Women, but not men, } \\
\text { derive benefit from CRT }\end{array}$ & Favours women \\
\hline RAFT $^{12,15}$ & 308 (17\%) & $\begin{array}{l}\text { NYHA class II-III } \\
\text { QRSd } \geq 120 \mathrm{~ms} \\
\text { LVEF } \leq 30 \%\end{array}$ & ICD versus CRT-D & Death or HF hospitalisation & $\begin{array}{l}\text { Women: } 0.52(0.35-0.85) \\
\text { Men: } 0.82(0.70-0.95)\end{array}$ & Favours women \\
\hline REVERSE $^{10}$ & $131(22 \%)$ & $\begin{array}{l}\text { NYHA class I-II } \\
\text { QRSd } \geq 120 \mathrm{~ms} \\
\text { LVEF } \leq 40 \% \\
\text { LVEDD } \geq 55 \mathrm{~mm}\end{array}$ & CRT-ON versus CRT-OFF & $\begin{array}{l}\text { HF clinical composite } \\
\text { endpoint }\end{array}$ & $\begin{array}{l}\text { Women: } 0.75(0.26-2.19) \\
\text { Men: } 0.69(0.43-1.11)\end{array}$ & No sex difference \\
\hline
\end{tabular}

$\mathrm{Cl}=$ confidence interval; $C R T-D=$ cardiac resynchronisation therapy defibrillator; $C R T-P=$ cardiac resynchronisation therapy pacemaker; $H F=$ heart failure; $H R=$ hazard ratio; $I C D=$ implantable cardioverter-defibrillator; LVEDD = left ventricular end-diastolic diameter; $L V E D D i=\angle V E D D$ indexed to body surface area; $L V E F=$ left ventricular ejection fraction; NYHA = New York Heart Association; OMT = optimal medical therapy; QRSd = QRS duration.

Table 2: Large studies (>10,000 patients) comparing clinical cardiac resynchronisation therapy outcome between women and men

\begin{tabular}{|c|c|c|c|c|c|c|c|c|}
\hline Study & Women, n (\%) & Design & Restrictions & $\begin{array}{l}\text { Time } \\
\text { period }\end{array}$ & $\begin{array}{l}\mathrm{HR}(95 \% \mathrm{Cl}) \text { death from } \\
\text { any cause; women } \\
\text { versus men }\end{array}$ & $\begin{array}{l}\text { HR }(95 \% \mathrm{Cl}) \text { death } \\
\text { or HF hospitalisation; } \\
\text { women versus men }\end{array}$ & $\begin{array}{l}\text { HR }(95 \% \mathrm{Cl}) \mathrm{HF} \\
\text { hospitalisation; } \\
\text { women versus men }\end{array}$ & Conclusion \\
\hline Cheng et al. ${ }^{18}$ & 8,058 (24\%) & $\begin{array}{l}\text { Meta-analysis of } \\
72 \text { studies }\end{array}$ & None & 1966-2014 & $0.67(0.61-0.74)$ & $0.80(0.71-0.90)$ & $0.58(0.44-0.76)$ & $\begin{array}{l}\text { Favours } \\
\text { women }\end{array}$ \\
\hline Han et al. ${ }^{19}$ & $7,952(23 \%)$ & $\begin{array}{l}\text { Meta-analysis of } \\
58 \text { studies }\end{array}$ & None & 1980-2016 & $0.67(0.62-0.73)$ & NA & $0.58(0.46-0.74)$ & $\begin{array}{l}\text { Favours } \\
\text { women }\end{array}$ \\
\hline Leyva et al. ${ }^{20}$ & $10,890(25 \%)$ & $\begin{array}{l}\text { Retrospective } \\
\text { analysis national } \\
\text { database, England }\end{array}$ & None & 2009-2016 & $0.73(0.69-0.76)^{*}$ & $0.79(0.75-0.82)^{*}$ & NA & $\begin{array}{l}\text { Favours } \\
\text { women }\end{array}$ \\
\hline Loring et al. ${ }^{21}$ & $37,167(26 \%)$ & $\begin{array}{l}\text { Retrospective } \\
\text { analysis of Medicare } \\
\text { records, USA }\end{array}$ & Only CRT-D & 2002-2008 & $0.84(0.82-0.85)$ & $0.90(0.88-0.92)$ & NA & $\begin{array}{l}\text { Favours } \\
\text { women }\end{array}$ \\
\hline Yin et al. ${ }^{22}$ & $38,226(26 \%)$ & $\begin{array}{l}\text { Meta-analysis of } \\
11 \text { studies }\end{array}$ & None & Up to 2016 & $0.50(0.36-0.70)^{\dagger}$ & NA & NA & $\begin{array}{l}\text { Favours } \\
\text { women }\end{array}$ \\
\hline $\begin{array}{l}\text { Zusterzeel } \\
\text { et al. }{ }^{23}\end{array}$ & $11,542(36 \%)$ & $\begin{array}{l}\text { Retrospective } \\
\text { analysis of national } \\
\text { database, USA }\end{array}$ & Only CRT-D & 2006-2009 & $0.82(0.78-0.87)$ & NA & NA & $\begin{array}{l}\text { Favours } \\
\text { women }\end{array}$ \\
\hline
\end{tabular}

\section{* Adjusted $H R ;^{\dagger}$ Odds ratio.}

$\mathrm{Cl}=$ confidence interval; $C R T-D=$ cardiac resynchronisation therapy defibrillator; $H F=$ heart failure; $H R=$ hazard ratio; $N A=$ not available.

\section{Natural history of heart failure}

It should be considered that survival in patients with heart failure who receive CRT is dependent on (i) patient profile, and (ii) the effect of CRT. As most of the evidence comes from observational (i.e., non-randomised) studies, favourable outcome of women could be partially ascribed to a better natural history in heart failure (irrespective of the effect of CRT). In a large meta-analysis including almost 42,000 patients with heart failure without CRT (33\% women), risk factors differed between men and women, with the latter being older and more likely to have hypertension, but less likely to have a history of ischaemic heart disease or reduced LVEF. ${ }^{27}$ The main finding of this study was that survival is better for women with heart failure (hazard ratio [HR] 0.81, 95\% confidence interval $[\mathrm{CI}]$ 0.78-0.85), irrespective of LVEF. Linde et al. performed a risk assessment for QRS width and morphology in nearly 15,000 patients with heart failure without CRT ( $28 \%$ women) and found that LBBB appeared to be harmful in men only. ${ }^{28}$ These results suggest that female CRT candidates may have a priori better survival, irrespective of CRT. 
Figure 1: Clinical outcome after cardiac resynchronisation therapy stratified by sex

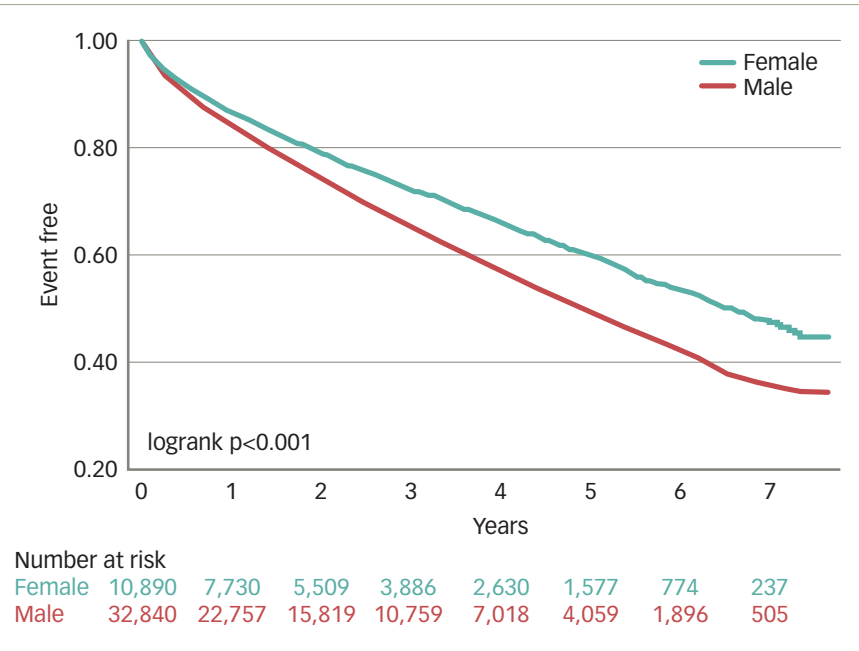

Kaplan-Meier curves for death or heart failure hospitalisation according to sex in a large English cardiac resynchronisation therapy database comprising almost 44,000 patients (25\% women).

Adapted with permission from Leyva et al. 2019.20

\section{Heart failure aetiology}

Ischaemic cardiomyopathy (ICM) is more prevalent in men, whereas women are more likely to have non-ischaemic cardiomyopathy (NICM). Loring et al. studied 235 patients (24\% women) who underwent cardiac magnetic resonance (CMR) imaging before ICD or CRT-D implantation. ${ }^{29}$ Among the CRT subgroup, women had smaller myocardial scar size (1\% versus 13\%) and less transmural extents compared with men, particularly involving the inferolateral region (i.e., the target area for the left ventricular [LV] lead). In other words, women have more viable myocardium that can be recruited by CRT and less (ineffective) stimulation within scar tissue. Accordingly, patients with NICM have shown to exhibit greater reverse remodelling and better outcomes compared with those with ICM. 13,30 Moreover, some studies suggested sex differences in CRT outcome to be almost entirely explained by differences in aetiology. ${ }^{31,32}$ In contrast, Leyva et al. showed in their large observational study of 44,000 patients (25\% women) that sex-specific differences in CRT outcomes persisted after separating groups by history of myocardial infarction. ${ }^{20}$ In the group of patients without myocardial infarction, females had significantly better clinical outcomes compared with men, although no sex-specific differences were observed in the group with myocardial infarction. These results are in line with a study by Mooyaart et al. showing that within subgroups divided by sex and aetiology, women with NICM had the best survival rate. ${ }^{33}$ These findings suggest that differences in aetiology play a large, but not decisive, role in sex-specific differences in CRT outcome.

\section{Delivery of therapy}

The effect of CRT depends, among many factors, on device programming, the percentage of effective biventricular pacing, and LV lead placement. Cheng et al. sought to explore potential mechanisms of why sex differences exist, using data from 846 patients (33\% women) from the SMART-AV trial. ${ }^{34}$ It was demonstrated that women derived greater reverse remodelling with CRT than men. These differences were explained by enhanced response to atrioventricular optimisation and greater degrees of biventricular pacing in women. Other studies confirmed a higher percentage of biventricular pacing in women, probably due to a lower rate of atrial fibrillation compared with men. 14,16,33,35,36 Auricchio et al. found in the European multicentre CRT Survey II, containing over 11,000 patients
Figure 2: Distribution of QRS duration and proportion of left bundle branch block in patients with heart failure

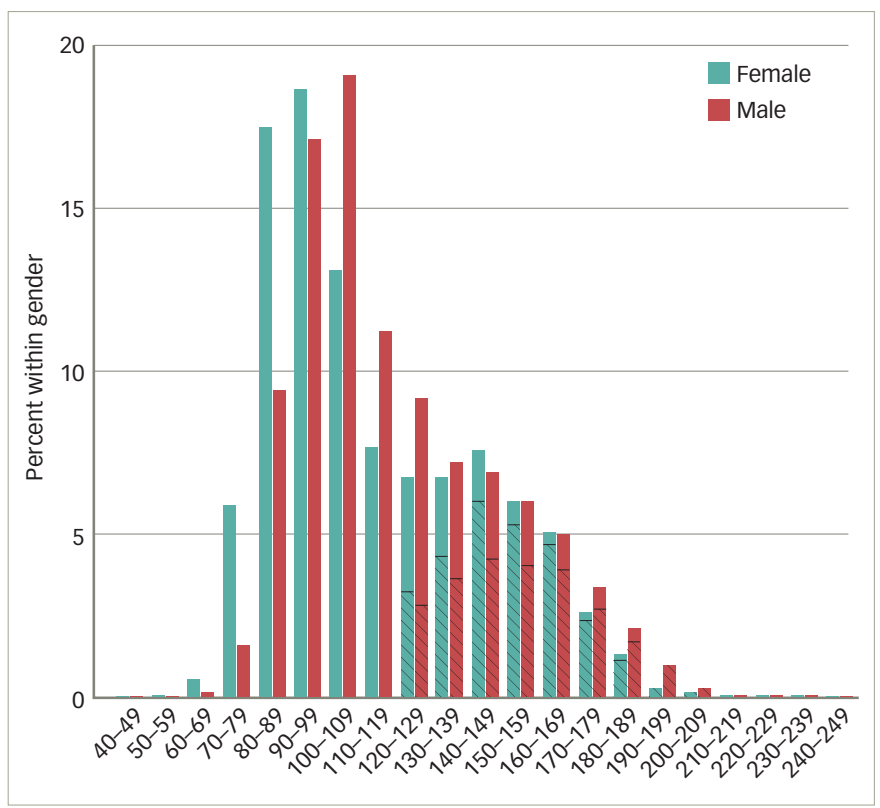

The percentage of patients within 10 ms QRS duration intervals, as well as the proportion of LBBB (hashed bars), is shown for men (red) and women (green). Women had narrower QRS, but once QRS duration was $\geq 120 \mathrm{~ms}$, the proportion of LBBB waS more common in women compared with men. $\angle B B B=$ left bundle branch block. Adapted with permission from Linde et al. 2015.28

(24\% women), that women were more frequently implanted with a basal LV lead position and had larger reduction in QRS duration during CRT compared with men. ${ }^{35}$ In contrast, the distribution of the LV lead in the anterior, lateral and posterior position was comparable between sexes.

\section{Mode of death}

The mode of death in patients with heart failure can be defined as arrhythmic, pump failure or non-cardiac. Rho et al. studied a large cohort of 8,000 patients with heart failure (20\% women) who potentially fulfilled eligibility criteria for implantation of an ICD for primary prevention of sudden cardiac death. ${ }^{37}$ Significant differences in mode of death were observed between sexes, with a lower proportional risk for sudden death (42\% versus $50 \%$ ) and higher proportional risk for pump failure death (36\% versus $29 \%$ ) in women compared with men. Given this finding, women will experience proportionately more benefit from CRT, which has been proven to significantly decrease mortality from pump failure deaths.7-12 In contrast, men are more likely to benefit from ICD implantation. ${ }^{38,39}$ These differences may be partly explained by the higher rate of NICM in women. Results from the randomised controlled DANISH trial with over 1,000 patients with heart failure (28\% women) and the majority (58\%) being equipped with CRT showed that prophylactic ICD implantation in patients with heart failure with NICM did not improve survival compared to standard care. ${ }^{40}$ These findings raise the question of whether adding prophylactic ICD therapy to CRT implantation (i.e., CRT-D) provides any benefit over CRT only (i.e., CRT pacemaker) in women who pre-dominantly have NICM. ${ }^{15,20,36,41}$

\section{Electrical dyssynchrony}

Normal QRS duration values are dependent on sex and race. ${ }^{42}$ Randolph et al. aimed to study QRS duration and morphology characteristics within the specific heart failure population amongst nearly 2,500 patients with reduced LVEF $\leq 35 \% .{ }^{43}$ Although median QRS duration was $\sim 5$ ms shorter for women compared with men, LBBB was 
Figure 3: Relation between QRS duration and cardiac resynchronisation therapy response rates by sex
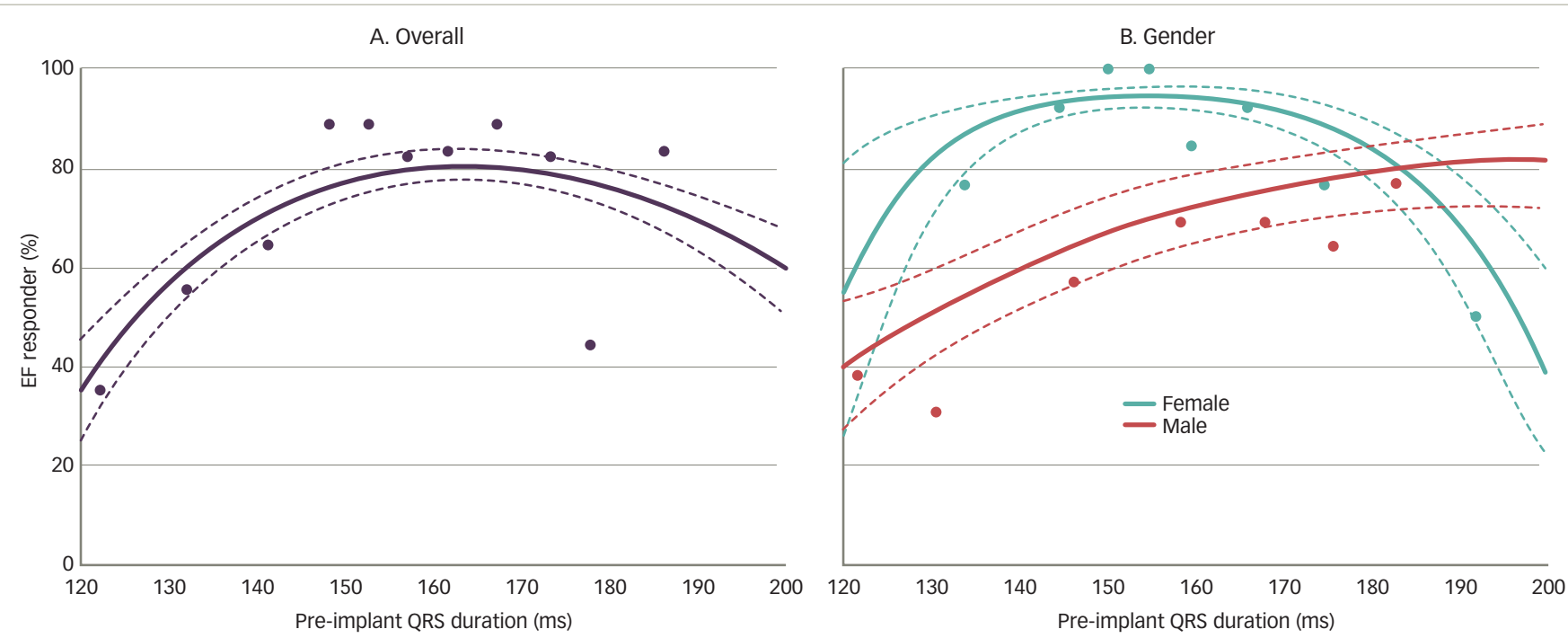

The relationship between pre-implantation QRS duration and cardiac resynchronisation response follows a non-linear curve (A). In women, response rates increase steeply at short QRS duration compared with a slow progressive rise in men (B).

$E F=$ ejection fraction.

Adapted with permission from Varma et al. 2014. ${ }^{46}$

more common in women (24\% versus $14 \%)$. These results indicate that at any given QRS duration, women might exhibit more substrate for electrical resynchronisation than men. This was confirmed by Linde et al. showing that women had LBBB morphology at narrower QRS duration (Figure 2). ${ }^{28}$ Using identical QRS duration cut-off criteria for men and women will therefore lead to the selection of women with more severe conduction disorder (i.e., true LBBB). In line with this concept, three large echocardiographic CRT studies (each containing over 1,000 patients) demonstrated that women more frequently have mechanical dyssynchrony (septal flash or apical rocking) at shorter QRS duration compared with males. ${ }^{31,44,45}$ This is an important finding as the correction of inefficient mechanical contraction underlies LV pump function improvement after CRT.

Varma et al. compared QRS duration-CRT response relations in 212 patients (50\% women) with $\mathrm{NICM}$ and LBBB. $^{46}$ Women showed a different QRS duration-CRT response relation than men with relatively more benefit at shorter QRS duration (particularly <150 ms) (Figure 3). ${ }^{46}$ Moreover, multiple studies evaluated the prognostic significance of LBBB detection according to sex. The largest of these studies was performed by Loring et al., analysing Medicare billing data of almost 145,000 patients undergoing CRT (26\% women) in the USA. ${ }^{21}$ LBBB diagnosis was associated with a $26 \%$ mortality reduction in women (HR $0.74,95 \% \mathrm{Cl} 0.71-0.77$ ) and a $15 \%$ mortality reduction in men (HR 0.85 , $95 \% \mathrm{Cl} 0.83-0.87$ ), with a significant interaction between sex and LBBB. In addition, Zusterzeel et al. studied nearly 32,000 CRT-D recipients (36\% women) from the USA national cardiovascular data registry and found that women had a $21 \%$ lower mortality risk than men (HR $0.79,95 \% \mathrm{Cl}$ $0.74-0.84)$; however, there was no difference in non-LBBB patients (HR 0.95, 95\% Cl 0.85-1.06). ${ }^{23}$ Lastly, women with LBBB in the MADIT-CRT study achieved a significantly better result with CRT than their male counterparts. ${ }^{14,47}$ In summary, considerable differences are observed in women regarding the manifestation of substrate for electrical resynchronisation (at shorter QRS duration) and the prognostic significance of LBBB diagnosis (more benefit from CRT). These differences may be explained by differences in heart size as will be discussed in the following section.
Figure 4: Effect of QRS duration normalisation to left ventricular size between sexes

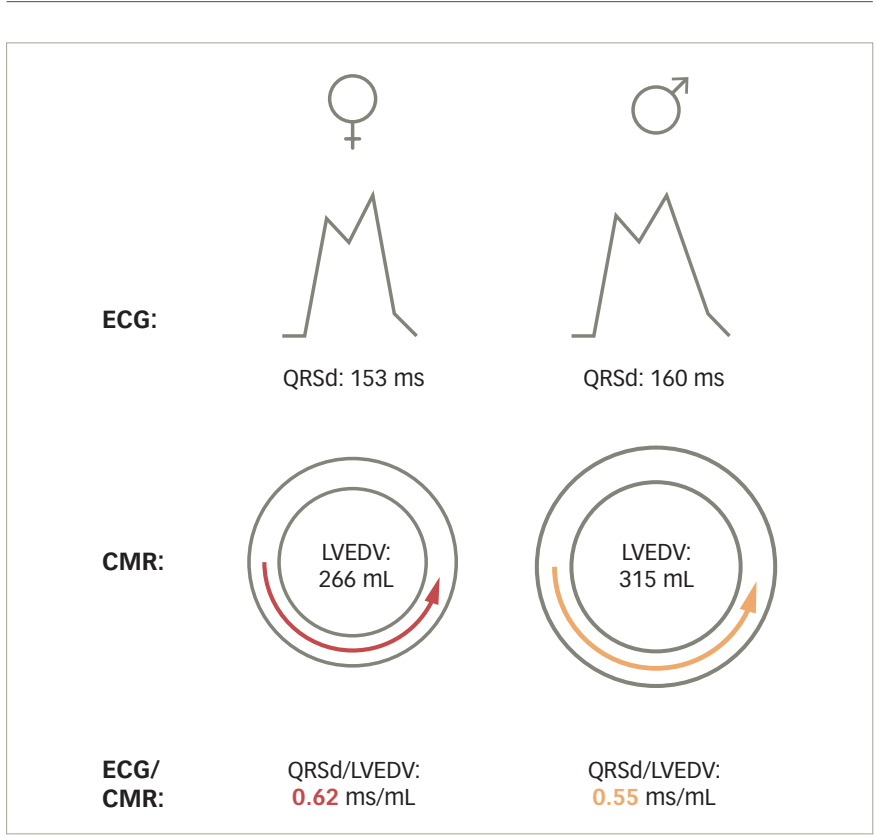

Women demonstrate shorter QRSd than men, but also have substantially smaller LVEDV. As a result, the QRSd:LVEDV ratio is higher in women, indicating lower conduction speed.

$C M R=$ cardiac magnetic resonance; $E C G$ = electrocardiogram; $L V E D V=$ left ventricular end-diastolic volume; $Q R S d=Q R S$ duration.

Adapted with permission from Zweerink et al. 2018.64

\section{Heart size}

In healthy subjects, women demonstrate up to $20 \%$ smaller LV dimensions compared with men. ${ }^{48}$ Throughout the heart failure course, women generally maintain relatively normal LV size, whereas men suffer from adverse cardiac remodelling, further amplifying differences in heart size. ${ }^{49}$ Theoretically, QRS duration is determined by both myocardial conduction velocity (i.e., substrate) and travel distance of the wave front (i.e., heart size). In line with this concept, a positive correlation exists between LV volumes or mass and QRS duration in both narrow QRS and LBBB. ${ }^{50}$ 
Figure 5: Overview of mechanisms explaining sex differences in cardiac resynchronisation therapy outcome ${ }^{23,29,31,34,48,64}$

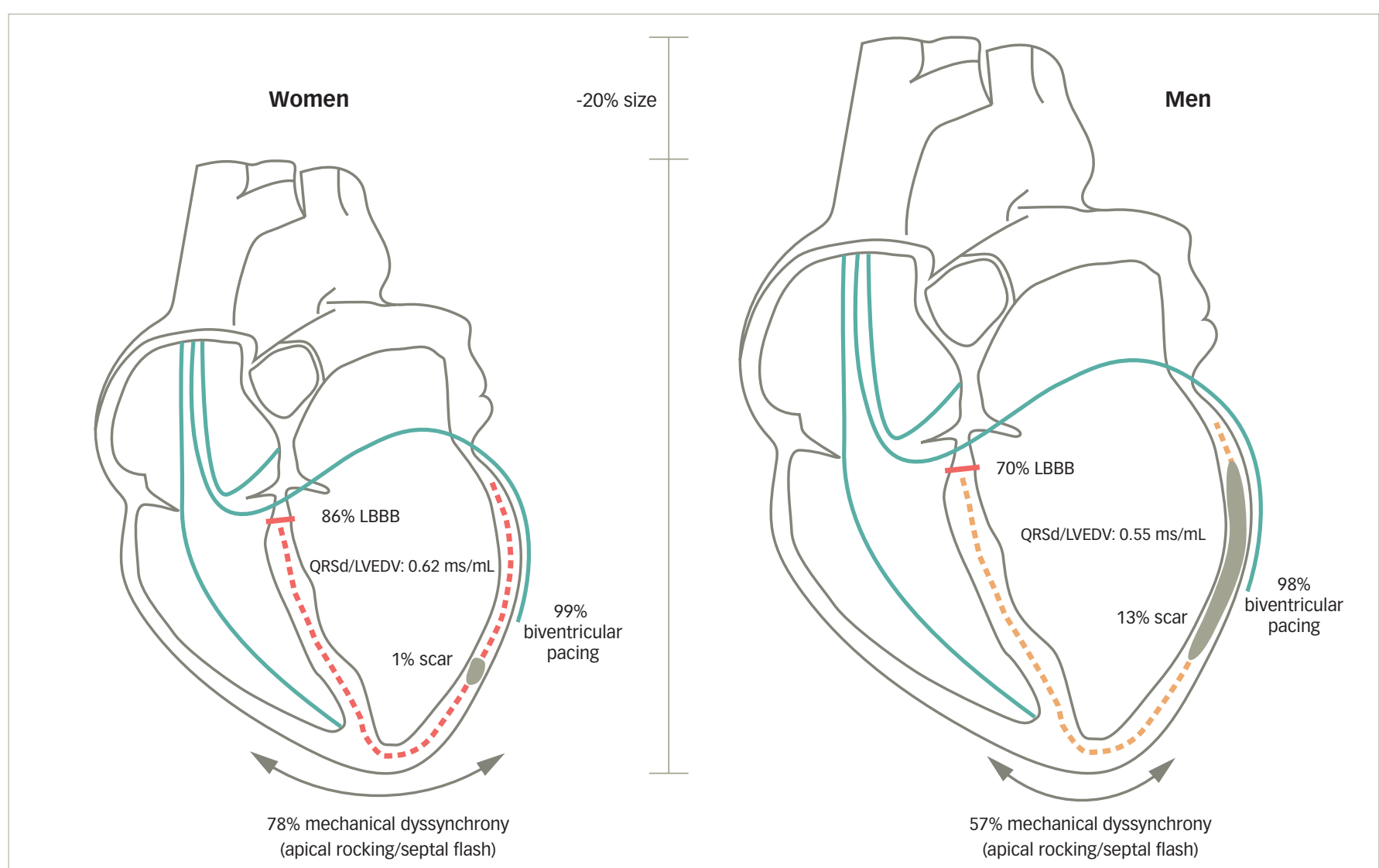

In summary, women have smaller heart size, smaller scar size, larger percentage biventricular pacing, more often LBBB morphology, higher ratio of QRSd:LVEDV indicating lower conduction velocity, and more mechanical dyssynchrony.

$\angle B B B=$ left bundle branch block; LVEDV = left ventricular end-diastolic volume; $Q R S d=Q R S$ duration.

De Pooter etal. demonstrated that LV size was an independent predictor of LBBB-QRS duration among more than 1,000 CRT patients (41\% women). ${ }^{44}$ Moreover, Lee et al. recently showed with computer simulations that LV size accounts for $50-100 \%$ of the QRS duration differences between CRT candidates. ${ }^{51}$ Sex differences in heart size will thus lead to considerable longer QRS duration in men.52

Although QRS duration prolongation is expected to result in improved CRT benefit, advanced LV dilation is actually associated with poor CRT outcome. ${ }^{53-56}$ Guo et al. showed that a wide QRS complex better predicted CRT response in absence of LV dilatation; ${ }^{57}$ however, these results were contradicted by Rickard et al. ${ }^{58}$ Linde et al. found in a meta-analysis of five randomised clinical trials that accounting for patient height improved predictive value of QRS duration for clinical outcome after CRT, although part of this effect may also be ascribed to differences in heart size. ${ }^{17}$ As heart size can be considered a confounder in the assessment of electrical dyssynchrony between men and women, normalisation of QRS duration to LV size may be considered to improve patient selection for CRT.

Several studies have called for new sex-specific CRT guidelines, either by lowering QRS duration cut-off values by 10 ms for women, $3-6,4,51,59$ or by providing a higher class of recommendation (i.e., class I indication) in women with LBBB and QRS duration $<150 \mathrm{~ms} .{ }^{16,23,46,47}$ Although these measures are likely to improve patient selection for women, men would still be subject to overtreatment. Moreover, simply subtracting a fixed $10 \mathrm{~ms}$ in women may not be sufficient to equalize sex-differences as this 'frameshift' would not superimpose the QRS duration-CRT response curves as shown in Figure 3.46
Recently, we proposed an alternative method to improve patient selection in both men and women by showing that normalising QRS duration to LV dimension, to adjust for differences in heart size, improved prediction of CRT response. ${ }^{60}$ In this proof-of-concept study, 32 patients (38\% women) underwent pre-implantation CMR imaging followed by invasive pressure-volume loop measurements directly after CRT implantation. It was demonstrated that unadjusted QRS duration was unrelated to haemodynamic changes during CRT, whereas normalisation of QRS duration to LV dimension resulted in a good correlation with acute haemodynamic CRT response. Women displayed a higher QRS duration:LVEDV ratio (due to smaller ventricles) indicating slower conduction at baseline, and showed more LV pump function improvement during CRT compared with men. In a subsequent study by Varma et al. with 130 patients (55\% women), sex-specific differences in the QRS duration-response relationship (Figure 3) resolved after QRS duration was normalised to LV dimension..$^{61}$ In addition, analysis of 787 patients ( $28 \%$ women) with narrow QRS duration ( $<130 \mathrm{~ms}$ ) in the ECHO-CRT study showed that most of the harmful effects of CRT were observed in men with a low QRS duration:LVEDV ratio, whereas women with a higher QRS duration:LVEDV ratio exhibited significant reverse remodelling. ${ }^{62,63}$

Most recently, the role of QRS duration normalisation was extended to the prediction of clinical outcome in a large two-centre study including 250 patients (34\% women) who underwent pre-implantation CMR imaging. ${ }^{64}$ First, normalisation of QRS duration to LV dimension improved prediction of survival after CRT implantation in the total population. Second, women demonstrated shorter QRS duration than men but also substantially smaller heart size, resulting in a higher QRS duration:LVEDV 
Table 3: Mechanisms of sex differences in cardiac resynchronisation therapy outcome

\begin{tabular}{|l|l|}
\hline Mechanism & Sex difference \\
\hline Natural history of HF & $\begin{array}{l}\text { - Women have better survival without CRT } \\
\text { - Women derive possibly less harm from LBBB without CRT }\end{array}$ \\
\hline HF aetiology & $\begin{array}{l}\text { - Women have less often ICMP and smaller scar size leading to more reverse remodelling } \\
\text { - Women have less (ineffective) pacing in scar tissue }\end{array}$ \\
\hline Delivery of therapy & $\begin{array}{l}\text { - Women benefit more from AV optimisation } \\
\text { - Women have a higher percentage biventricular pacing }\end{array}$ \\
\hline Mode of death & $\begin{array}{l}\text { - Women die more often from pump failure and potentially benefit from CRT } \\
\text { - Men die more often from arrhythmia and potentially benefit from ICD }\end{array}$ \\
\hline Electrical dyssynchrony & $\begin{array}{l}\text { - Women have shorter QRSd but more often LBBB morphology } \\
\text { - Women display substrate for electrical resynchronisation at shorter QRSd } \\
\text { - LBBB diagnosis shows larger prognostic significance in women }\end{array}$ \\
\hline Heart size & $\begin{array}{l}\text { - Women have smaller ventricles (i.e., shorter conduction path length) } \\
\text { - Increases in QRSd indicate a lower conduction speed as reflected by higher QRSd/LVEDV values }\end{array}$ \\
\hline
\end{tabular}

$A V=$ atrioventricular; $C R T=$ cardiac resynchronisation therapy; $H F=$ heart failure; ICD = implantable cardioverter-defibrillator; ICMP = ischemic cardiomyopathy; $L B B B=$ left bundle branch block; LVEDD = left ventricular end-diastolic diameter; QRSd = QRS duration.

ratio as illustrated in Figure $4 .{ }^{64}$ Third, sex-specific differences in CRT outcome were found to be explained by normalised QRS duration, rather than sex itself, in multivariable analysis.

\section{Conclusions}

Multiple mechanisms can be held accountable for the sex difference in CRT outcome as summarised in Figure 523,29,31,34,48,64 and Table 3. Women exhibit different risk factors resulting in better heart failure prognosis, irrespective of CRT. They more often display factors associated with good response to CRT, such as NICM with lower scar burden and
LBBB at shorter QRS duration, possibly due to smaller heart size. Conflicting evidence exists as to whether differences in CRT outcome can be attributed to these factors, ${ }^{14,17,19,31,32,54,57,61,64}$ or if after correction a true sex difference exists. $15,20,21,33,3,45,4,47,58$ Possibly, other biological factors such as hormonal differences and disparities in cardiac autonomic physiology come into play. ${ }^{65}$ Ultimately, understanding sex differences plays a pivotal role for the development of new strategies to equalize sex differences in CRT such as normalisation of QRS duration to LV size. Prospective studies are needed to evaluate the effect of these measures.
1. Ponikowski P, Voors AA, Anker SD, et al. 2016 ESC Guidelines for the diagnosis and treatment of acute and chronic heart failure: The Task Force for the diagnosis and treatment of acute and chronic heart failure of the European Society of Cardiology (ESC)Developed with the special contribution of the Heart Failure Association (HFA) of the ESC. Eur Heart I 2016;37:2129-200

2. Yancy CW, Jessup M, Bozkurt B, et al. 2013 ACCF/AHA guideline for the management of heart failure: a report of the American college of Cardiology Foundation/American Heart Association Task Force on Practice Guidelines. I Am Coll Cardiol. 2013:62:e147-239.

3. Germany RE, Ripley TL. Controversies in cardiac resynchronization therapy: do sex differences in response exist? Curr Heart Fail Rep. 2011;8:59-64

4. Lee NS, Lin F, Birgersdotter-Green U. Should women have different ECG criteria for CRT than men? J Cardiol. 2017;70:1-6.

5. Nishimura M, Birgersdotter-Green U. Gender-based differences in cardiac resynchronization therapy response. Card Electrophysiol Clin. 2019;11:115-22.

6. Zusterzeel R, Selzman KA, Sanders WE, et al. Toward sex-specific guidelines for cardiac resynchronization therapy? J Cardiovasc Transl Res. 2016;9:12-22.

7. Abraham WT, Fisher WG, Smith AL, et al. Cardiac resynchronization in chronic heart failure. $N$ Eng/ I Med 2002;346:1845-53

8. Bristow MR, Saxon LA, Boehmer J, et al. Cardiac-resynchronization therapy with or without an implantable defibrillator in advanced chronic heart failure NEng/ I Med. 2004:350:2140-50.

9. Cleland JG, Daubert JC, Erdmann E, et al. The effect of cardiac resynchronization on morbidity and mortality in heart failure. N Engl J Med. 2005;352:1539-49.

10. Daubert C, Gold MR, Abraham WT, et al. Prevention of disease progression by cardiac resynchronization therapy in patients with asymptomatic or mildly symptomatic left ventricular dysfunction: insights from the European cohort of the REVERSE (Resynchronization Reverses Remodeling in Systolic Left Ventricular Dysfunction) trial. J Am Coll Cardiol. 2009;54:1837-46.

11. Moss AJ, Hall WJ, Cannom DS, et al. Cardiac-resynchronization therapy for the prevention of heart-failure events. N Eng/ J Med. 2009;361:1329-38

12. Tang AS, Wells GA, Talajic M, et al. Cardiac-resynchronization therapy for mild-to-moderate heart failure. $N$ Eng/ I Med. 2010;363:2385-95

13. Woo GW, Petersen-Stejskal S, Johnson JW, et al. Ventricula reverse remodeling and 6-month outcomes in patients receiving cardiac resynchronization therapy: analysis of the MIRACLE study. J Interv Card Electrophysiol. 2005;12:107-13.

14. Arshad A, Moss AJ, Foster E, et al. Cardiac resynchronization therapy is more effective in women than in men: the MADIT-CRT (Multicenter Automatic Defibrillator Implantation Trial with Cardiac Resynchronization Therapy) trial. J Am Coll Cardiol. 2011;57:813-20.

15. de Waard D, Manlucu J, Gillis AM, et al. Cardiac resynchronization in women: a substudy of the resynchronization-defibrillation for ambulatory heart failure trial. JACC Clin Electrophysiol. 2019;5:1036-44.

16. Zusterzeel R, Selzman KA, Sanders WE, et al. Cardiac resynchronization therapy in women: US Food and Drug Administration meta-analysis of patient-level data. Administration meta-analysis of patient-
JAMA Intern Med 2014:174:1340-8.

17. Linde C, Cleland JGF Gold MR, et al. The interaction of sex, height, and QRS duration on the effects of cardiac resynchronization therapy on morbidity and mortality: an individual-patient data meta-analysis. Eur J Heart Fail. 2018;20:780-91.

18. Cheng YJ, Zhang J, Li WJ, et al. More favorable response to cardiac resynchronization therapy in women than in me Circ Arrhythm Electrophysiol. 2014;7:807-15.

19. Han Z, Chen Z, Lan R, et al. Sex-specific mortality differences in heart failure patients with ischemia receiving cardiac resynchronization therapy. PLOS One. 2017;12:e0180513

20. Leyva F, Qiu T, Zegard A, et al. Sex-specific differences in survival and heart failure hospitalization after cardiac resynchronization therapy with or without defibrillation. J Am Heart Assoc. 2019;8: 0013485

21. Loring Z, Canos DA, Selzman K, et al. Left bundle branch block predicts better survival in women than men receiving cardiac resynchronization therapy: long-term follow-up of approximately 145,000 patients. JACC Heart Fail. 2013;1:237-44.

22. Yin FH, Fan CL, Guo YY, et al. The impact of gender difference on clinical and echocardiographic outcomes in patients with heart failure after cardiac resynchronization therapy: a systematic review and meta-analysis. PLoS One 2017:12:e0176248.

23. Zusterzeel R, Curtis JP, Canos DA, et al. Sex-specific mortality risk by QRS morphology and duration in patients receiving CRT results from the NCDR. J Am Coll Cardiol. 2014;64:887-94.

24. Lund LH, Braunschweig F, Benson L, et al. Association between demographic, organizational, clinical, and socio-economic characteristics and underutilization of cardiac resynchronization therapy: results from the Swedish Heart resynchronization therapy: results from the swe
Failure Registry. Eur J Heart Fail. 2017:19:1270-9.

25. Chatterjee NA, Borgquist $R$, Chang $Y$, et al. Increasing sex differences in the use of cardiac resynchronization therapy with or without implantable cardioverter-defibrillator. Eur Heart J. 2017;38:1485-94.

26. Linde $\mathrm{C}$, Bongiorni MG, Birgersdotter-Green $\mathrm{U}$, et al. Sex differences in cardiac arrhythmia: a consensus document of the European Heart Rhythm Association, endorsed by the
Heart Rhythm Society and Asia Pacific Heart Rhythm Society. Europace. 2018;20:1565-1565a0.

27. Martinez-Selles M, Doughty RN, Poppe K, et al. Gender and survival in patients with heart failure: interactions with diabetes and aetiology. Results from the MAGGIC individual patient meta-analysis. Eur J Heart Fail. 2012;14:473-9.

28. Linde C, Stahlberg M, Benson L, et al. Gender, underutilization of cardiac resynchronization therapy, and prognostic impact of QRS prolongation and left bundle branch block in heart failure. Europace. 2015;17:424-31.

29. Loring Z, Strauss DG, Gerstenblith G, et al. Cardiac MRI scar patterns differ by sex in an implantable cardioverter-defibrillator and cardiac resynchronization therapy cardioverter-defibrillator and cardiac restic

30. Sutton MG, Plappert T, Hilpisch KE, et al. Sustained reverse left ventricular structural remodeling with cardiac resynchronization at one year is a function of etiology: quantitative doppler echocardiographic evidence from the Multicenter InSync Randomized Clinical Evaluation (MIRACLE). Circulation. 2006;113:266-72.

31. Beela AS, Duchenne J, Petrescu A, et al. Sex-specific difference in outcome after cardiac resynchronization therapy. Eur Heart Cardiovasc Imaging. 2019;20:504-11.

32. Xu YZ, Friedman PA, Webster T, et al. Cardiac resynchronization therapy: do women benefit more than men? J Cardiovasc Electrophysiol. 2012;23:172-8.

33. Mooyaart EA, Marsan NA van Bommel RJ, et al. Comparison of long-term survival of men versus women with heart failure treated with cardiac resynchronization therapy. Am I Cardiol. 2011;108:63-8.

34. Cheng A, Gold MR, Waggoner AD, et al. Potential mechanisms underlying the effect of gender on response to cardiac resynchronization therapy: insights from the SMART-AV multicenter trial. Heart Rhythm. 2012;9:736-41.

35. Auricchio A, Gasparini M, Linde C, et al. Sex-related procedural aspects and complications in CRT survey II: a multicenter European experience in 11,088 patients.
JACC Clin Electrophysiol. 2019;5:1048-58.

36. Schuchert A, Muto C, Maounis T, et al. Gender-related safety and efficacy of cardiac resynchronization therapy. Clin Cardiol. 2013;36:683-90

37. Rho RW, Patton KK, Poole JE, et al. Important differences in mode of death between men and women with heart failure who would qualify for a primary prevention implantable cardioverter-defibrillator. Circulation. 2012;126:2402-7.

38. Ghanbari H, Dalloul G, Hasan R, et al. Effectiveness of implantable cardioverter-defibrillators for the primary prevention of sudden cardiac death in women with advanced heart failure: a meta-analysis of randomized controlled trials. Arch Intern Med. 2009;169:1500-6.

39. Santangeli P, Pelargonio G, Dello Russo A, et al. Gender 
differences in clinical outcome and primary prevention defibrillator benefit in patients with severe left ventricular dysfunction: a systematic review and meta-analysis. Heart Rhythm. 2010:7:876-82.

40. Kober L, Thune JJ, Nielsen JC, et al. Defibrillator implantation in patients with nonischemic systolic heart failure. N Eng/ I Med. 2016:375:1221-30

41. Barra S, Providencia R, Duehmke R, et al. Sex-specific outcomes with addition of defibrillation to resynchronisation therapy in patients with heart failure. Heart. 2017;103:753-60.

2. Hnatkova K, Smetana P, Toman O, et al. Sex and race differences in QRS duration. Europace. 2016;18:1842-9.

43. Randolph TC, Broderick S, Shaw LK, et al. Race and sex differences in QRS interval and associated outcome among patients with left ventricular systolic dysfunction. J Am Heart Assoc. 2017;6:e004381.

44. De Pooter J, Kamoen V, El Haddad M, et al. Gender differences in electro-mechanical characteristics of left bundle branch cardiac resynchronization therapy. Int I Cardiol. 2018;257:84-91.

45. Stankovic I, Prinz C, Ciarka A, et al. Relationship of visually assessed apical rocking and septal flash to response and long-term survival following cardiac resynchronization therapy (PREDICT-CRT). Eur Heart J Cardiovasc Imaging. 2016;17:262-9

6. Varma N, Manne M, Nguyen D, et al. Probability and magnitude of response to cardiac resynchronization therapy according to QRS duration and gender in nonischemic cardiomyopathy and LBBB. Heart Rhythm. 2014;11:1139-47.

47. Biton Y, Zareba W, Goldenberg I, et al. Sex differences in long-term outcomes with cardiac resynchronization therapy in mild heart failure patients with left bundle branch block. J Am Heart Assoc. 2015:4:e002013.
48. Kawel-Boehm N, Maceira A, Valsangiacomo-Buechel ER, et al. Normal values for cardiovascular magnetic resonance in adults and children. J Cardiovasc Magn Reson. 2015;17:29.

49. Dunlay SM, Roger VL. Gender differences in the pathophysiology, clinical presentation, and outcomes of ischemic heart failure. Curr Heart Fail Rep. 2012;9:267-76.

50. Chan DD, Wu KC, Loring Z, et al. Comparison of the relation between left ventricular anatomy and QRS duration in patients with cardiomyopathy with versus without left bundle branch block. Am J Cardiol. 2014;113:1717-22.

51. Lee AWC, O'Regan DP, Gould J, et al. Sex-dependent QRS guidelines for cardiac resynchronization therapy using computer model predictions. Biophys J. 2019;117:2375-81.

52. Galeotti $L$, van Dam PM, Loring Z, et al. Evaluating strict and conventional left bundle branch block criteria using electrocardiographic simulations. Europace. 2013;15:1816-21.

53. Carluccio E, Biagioli P, Alunni G, et al. Presence of extensive $\mathrm{LV}$ remodeling limits the benefits of CRT in patients with intraventricular dyssynchrony. JACC Cardiovasc Imaging. 2011;4:1067-76.

54. Gasparini M, Regoli F Ceriotti C, et al. Remission of left ventricular systolic dysfunction and of heart failure symptoms after cardiac resynchronization therapy: temporal pattern and clinical predictors. Am Heart J. 2008:155:507-14.

55. Rickard J, Brennan DM, Martin DO, et al. The impact of left ventricular size on response to cardiac resynchronization therapy. Am Heart J. 2011;162:646-53.

56. Vidal B, Delgado V, Mont L, et al. Decreased likelihood of response to cardiac resynchronization in patients with severe heart failure. Eur J Heart Fail. 2010;12:283-7.

57. Guo Z, Liu X, Cheng X, et al. Combination of left ventricular end-diastolic diameter and QRS duration strongly predicts good response to and prognosis of cardiac resynchronization therapy. Cardiol Res Pract. 2020;2020:1257578

8. Rickard J, Baranowski B, Grimm RA, et al. Left ventricular size does not modify the effect of QRS duration in predicting response to cardiac resynchronization therapy. Pacing Clin Electrophysiol 2017:40:482-7.

59. Strauss DG, Selvester RH, Wagner GS. Defining left bundle branch block in the era of cardiac resynchronization therapy. Am J Cardiol 2011:107:927-34.

60. Zweerink A, Wu L, de Roest GJ, et al. Improved patient selection for cardiac resynchronization therapy by normalization of QRS duration to left ventricular dimension. Europace. 2017;19:1508-13

61. Varma N, Lappe J, He J, et al. Sex-specific response to cardiac resynchronization therapy: effect of left ventricular size and QRS duration in left bundle branch block. JACC Clin Electrophysiol. 2017;3:844-53

62. Varma N, Sogaard P, Bax JJ, et al. Interaction of left ventricular size and sex on outcome of cardiac resynchronization therapy among patients with a narrow QRS duration in the EchoCRT trial. J Am Heart ASSOC. 2018; 7:e009592.

63. Steffel J, Varma N, Robertson M, et al. Effect of gender on outcomes after cardiac resynchronization therapy in patients with a narrow QRS complex: a subgroup analysis of the EchoCRT trial. Circ Arrhythm Electrophysiol. 2016;9:e003924.

64. Zweerink A, Friedman DJ, Klem I, et al. Size matters: normalization of QRS duration to left ventricular dimension improves prediction of long-term cardiac resynchronization therapy outcome. Circ Arrhythm Electrophysiol. 2018;11:e006767.

65. Mitoff PR, Gam D, Ivanov J, et al. Cardiac-specific sympathetic activation in men and women with and without heart failure. Heart. 2011;97:382-7. 